

\section{Voguing, un grito retorcido contra la opresión. Soy todo y nada, sobre la danza de cuerpos desviantes}

\section{Artículo de investigación}

Recibido: 1 de agosto de 2020

Aprobado: 13 de octubre de 2020

\section{Lucelina Nunes Barbosa}

Secretaria de Cultura de la Ciudad de México, México

Escuela de Danza Contemporánea del Centro Cultural Ollin Yoliztli, México

lucelina.nunes@gmail.com

Cómo citar este artículo: Nunes Barbosa, Lucelina (2021). Voguing, un grito retorcido contra la opresión. Soy todo y nada, sobre la danza de cuerpos desviantes. Estudios Artísticos: revista de investigación creadora, 7(10) pp. 144-161.

DOI: https://doi.org/10.14483/25009311.17518

\section{Agradecimientos}

A la Escuela de Danza Contemporánea del Centro Cultural Ollin Yoliztli y sus estudiantes, en especial los voguers que fueron la motivación de esta investigación. Al Doctorado Cartografía del Arte Contemporáneo liderado por Jorge Juanes, Sonia Rangel y Jonathan Caudillo. A Sofía Huerta Nunes por ser arte viva de mi esencia.

$<$

Alexis Córdoba/Zymalia Drag (2020). Fotógrafos: Isaac Sánchez y Mattias Alva. En Ciudad de México

\section{Resumen}

Este artículo es una aproximación al cuerpo desde la especificidad de la danza "voguing" y la noción de cuerpo no binario. Las reflexiones circundan los discursos de poder y dominación a que estamos subordinadas en nuestra cotidianidad y en el ámbito de la danza, y el "voguing" como expresión dancística activista de resistencia contra la marginación de grupos minoritarios integrados por gays, afroamericanos, migrantes latinos, transgéneros y queer. Este estilo dancístico y expresión de reafirmación social tipificó a la comunidad LGBTTTIQ en las décadas de 1980 y 1990. Abordamos aquí las prácticas corporales de jóvenes que bailan bajo la perspectiva de la diversidad y desarrollan diferentes abordajes somatopolíiticos con un particular interés en expresiones dancísticas que revelan el cuerpo como objeto de consumo y signo a la vez. Se indaga sobre las aprobaciones hegemónicas utilizadas por los "voguers" como reivindicación contestataria que reproduce gestos codificados de concepción binaria.

\section{Palabras claves}

Ballroom; cuerpo; danza; genero; performatividades; voguing

\section{Voguing, a Twisted Cry Against Oppression. I am Everything and Nothing - On the Dance of Deviant Bodies}

\footnotetext{
Abstract

This article is an approach to the body from the specificity of voguing and the notion of the non-binary body. Our reflections target the discourses of power and domination to which we are subordinate in our daily lives, and in the field of dance,
} 
as well as voguing as an activist expression of resistance against the marginalization of minority groups made up of gays, African Americans, Latino immigrants, transgender and queer people. This dance style and expression of social reaffirmation characterized the LGBTIQ community in the 1980s and 1990s. We address here the corporal practices of young people who dance from a perspective of diversity, developing different somatopolitical strategies, with a particular interest in dance expressions that reveal the body as an object of consumption and a sign at the same time. We research the hegemonic approvals used by the "voguers" as a rebellious claim that reproduces codified gestures of binary conception.

\section{Keywords}

Ballroom; body; dance; gender; performativities; voguing

\section{Voguing, un cri tordu contre I'oppression. Je suis tout et rien - Sur la danse des corps déviants}

\section{Résumé}

Cet article est une approche du corps à partir de la spécificité du voguing et de la notion de corps non binaire. Nos réflexions ciblent les discours de pouvoir et de domination auxquels nous sommes subordonnés dans notre vie quotidienne, et dans le domaine de la danse, ainsi que le « voguing » comme expression militante de résistance contre la marginalisation des groupes minoritaires constitués d’homosexuels, Afro-Américains, immigrés latinos, transgenres et queers. Ce style de danse et expression de la réaffirmation sociale ont caractérisé la communauté LGBTIQ dans les années 1980 et 1990. Nous abordons ici les pratiques corporelles des jeunes qui dansent dans une perspective de diversité, développant différentes stratégies somatopolitiques, avec un intérêt particulier pour les expressions de danse qui révèlent le corps comme objet de consommation et comme signe à la fois. Nous recherchons les approbations hégémoniques utilisé par les « voguers » comme une revendication rebelle qui reproduit des gestes codifiés de conception binaire.

\section{Mots clés}

Salle de bal ; corps ; danse ; genre ; performativités ; voguing

\section{Voguing um grito retorcido contra a opressão. Sou tudo e nada, sobre a dança de corpos desviantes.}

\section{Resumo}

Este artigo é uma aproximação ao corpo a partir da especificidade da dança "voguing" e da noção de corpo não binário. As reflexões circundam os discursos de poder e dominação que estamos subordinados em nossa cotidianidade e, no âmbito da dança o "Voguing", uma expressão ativista e de resistência em dança contra a marginalização de grupos minoritários integrados por gays afro americanos, migrantes latinos, transgêneros e queer. Um estilo de dança e expressão de reafirmação social que tipificou a comunidade LGBTTTIQ nas décadas de 1980 e 1990. Aborda as práticas corporais de jovens que dançam a partir da perspectiva da diversidade, desenvolvem diferentes abordagens somatopolíticas, com um interesse particular em expressões em dança, sobretudo aos usos do corpo como objeto de consumo e signo ao mesmo tempo. Se indaga sobre as aprovações hegemônicas utilizadas pelos "voguers" como reivindicação contestatária que reproduzem gestos codificados de concepção binária.

\section{Palavras chave}

Ballroom; corpo; dança; gênero; performatividades; voguing

\section{Nukanchi kulluriskata kaparispa ningapa kausachi. Kani Tukui, ñiman kani mullurispa nukanchi kikin maimapas}

\section{Maillallachiska}

Kai kilkapi nikumi imasami warmikuna kari tupuska munankuna mulluringa imasa munaskasina chasallata tiami kankuna warmi tukuska paikunapas. Mullurinkuna ajai suma kauachispa paikunapa kausaipas kaimi iapa, ministidu, kai samukumi ñugpamanda atun waranga iskun pusag chunga, watapi chiuramandata musu warmi karikuna mullurinkuna paikuna mukaskasina lurachingapa paikunapas charami kausankuna. Maituku wata llalispipas parlangapami kamkuna ima paikuna ruraska. 


\section{Rimangapa Ministidukuna}

ballroom Munaskasina mullurii; nukanchi kikin; warmi kari ima kaska; Achka ruraikuna; nukanchi kulluri voguing

¿Qué configuraciones asumen las performatividades queers en el ballroom y el voguing como espacio de transgresión, resistencia, expresión libre de deseos, sensualidades y protesta contra la marginación? ¿Qué narrativas corporales emergen en espacios públicos y privados, ante miradas opresivas que silencian expresividades y corporalidades diversas?

Este artículo es una aproximación al cuerpo desde la especificidad de la danza voguing y la noción de cuerpo no binario. Emerge del repensar las corporalidades desde sus recónditas y disimuladas contiendas con uno mismo, con el entorno y con la danza. Deviene del sinnúmero de interrogantes generadas en mi caminar por la vida, por la docencia y por la danza misma. Pulsión de cuerpo migrante que en la mimesis con un nuevo entorno genera preguntas que configuran una nueva forma de habitar el mundo. Surge, en gran parte, del cercano e íntimo convivio con diversidad de cuerpxs, ávidos de saberes, que generan digresiones y reflexiones en torno al cuerpo en la actualidad, en específico el cuerpo que danza.

Entre estas reflexiones me encuentro yo, un cuerpo extranjero desviante que en el encuentro con un nuevo contexto social se reconfigura e indaga sobre los discursos de poder y dominación que estamos subordinadas en nuestra cotidianidad. Dejé parte de mi cuerpo sensible allá, en aquél pasado reconfortante que resguardo con afecto en la memoria, me diluyo en aquel Brasil con nostalgia ¿Dónde quedaron aquellas calles calurosas, aquél cuerpo húmedo que paseaba con un fresco y ligero vestido transparente sobre la piel? Aquella piel semidesnuda que expresaba un caminar seguro sin opresión. Hoy inundan mi cuerpo miradas vertiginosas, conservadoras e incomodas, con otros olores y sabores, otra luz, miradas incisivas de cuerpos otros que imponen prohibición: "me come el entorno, me traga México". Ahora encuentro otra lectura del mundo, otra lectura del cuerpo y otra lectura de mí. De este cuerpo emergen preguntas que no puedo nombrar, las encierro y las cubro bajo el epitelio que silencia la frustración. Solo la danza y el movimiento posibilita el grito evasivo de la opresión, sólo el cuerpo en su ritmo más íntimo y sutil, posibilita la tímida sensación de secreta libertad.

La migración ha sido parte de la historia de la humanidad, supone la movilización, y el desplazamiento, el cambio, la expansión y por consecuencia la transformación del ser humano y de su mundo. Si la acción de migrar es el desplazamiento, por ende, es movimiento, fenómeno inherente a lo humano. La experiencia migratoria también es corporal, circunscribe el cuerpo en un ámbito en el que entrecruzan relaciones de poder, género, identidades, sexualidad y deseo. ¿Qué sucede con el cuerpo que migra?, ¿cómo el cuerpo es afectado por la migración y cómo afecta a otros cuerpos y su entorno?

Según Grosz (1995 y 1994) el cuerpo emerge como territorio decisivo para comprender las relaciones de poder y de género, la construcción de identidades, las formas de sexualidad, de resistencia y liberación. Foucault (1978 y 1988) detalla el cuerpo como un complejo campo de relaciones de poder, disciplinas y tecnologías sociales que objetivan conformar un tipo específico de sujeto bajo ciertos parámetros morales y políticos. Señala que en toda sociedad, el cuerpo "queda prendido en el interior de poderes muy ceñidos, que le imponen coacciones, interdicciones u obligaciones" (Foucault, 1981a, p. 140). Judith Butler (1990, 1993 y 2005) retoma esta aproximación microfísica del poder y logra un espacio relevante en los debates sobre el signo corporal de la experiencia, del poder, del deseo y de la opresión.

La confluencia, cuerpo e historia en Foucault, delimita por un lado, que no existe nada natural en la manera de relacionarse con el cuerpo, y por el otro, a grandes rasgos señala que: "el cuerpo, al convertirse en blanco de nuevos mecanismos de poder, se ofrece a nuevas formas de saber" (Foucault, 1981b, p. 159). Si el cuerpo es perpetrador de la historia, la historia se hace carne en el cuerpo. El cuerpo redacta la historia y la historia se inscribe en el cuerpo, que a su vez es sucesión de movimientos y gestos cargados de acontecimientos que pincelan escalas de género, raza y clases sociales. El cuerpo que coreografía gestos y traza performatividades permite analizar y reflexionar sobre cómo las minorías abordan narrativas alternas para crear formas disidentes de belleza, subjetividad y deseo. 


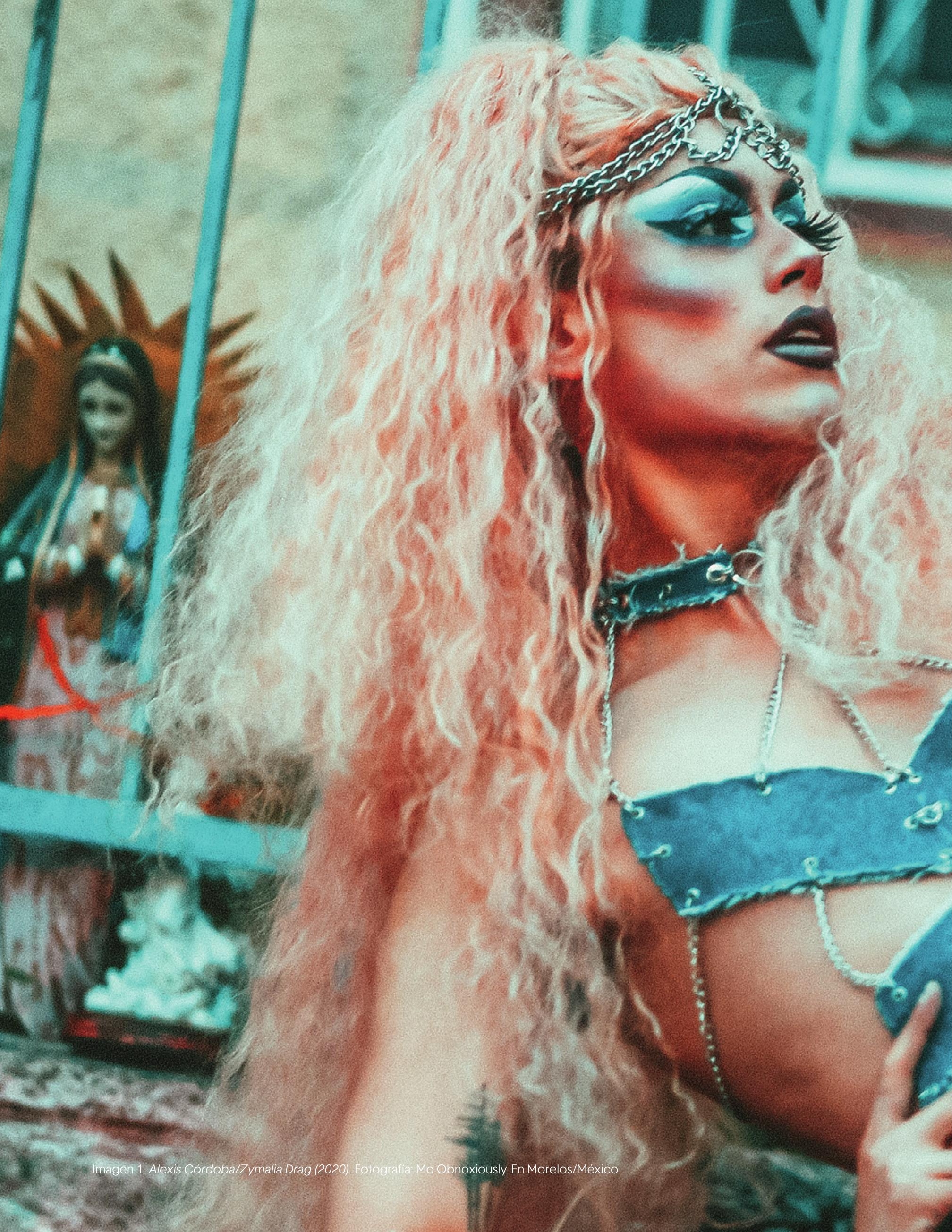




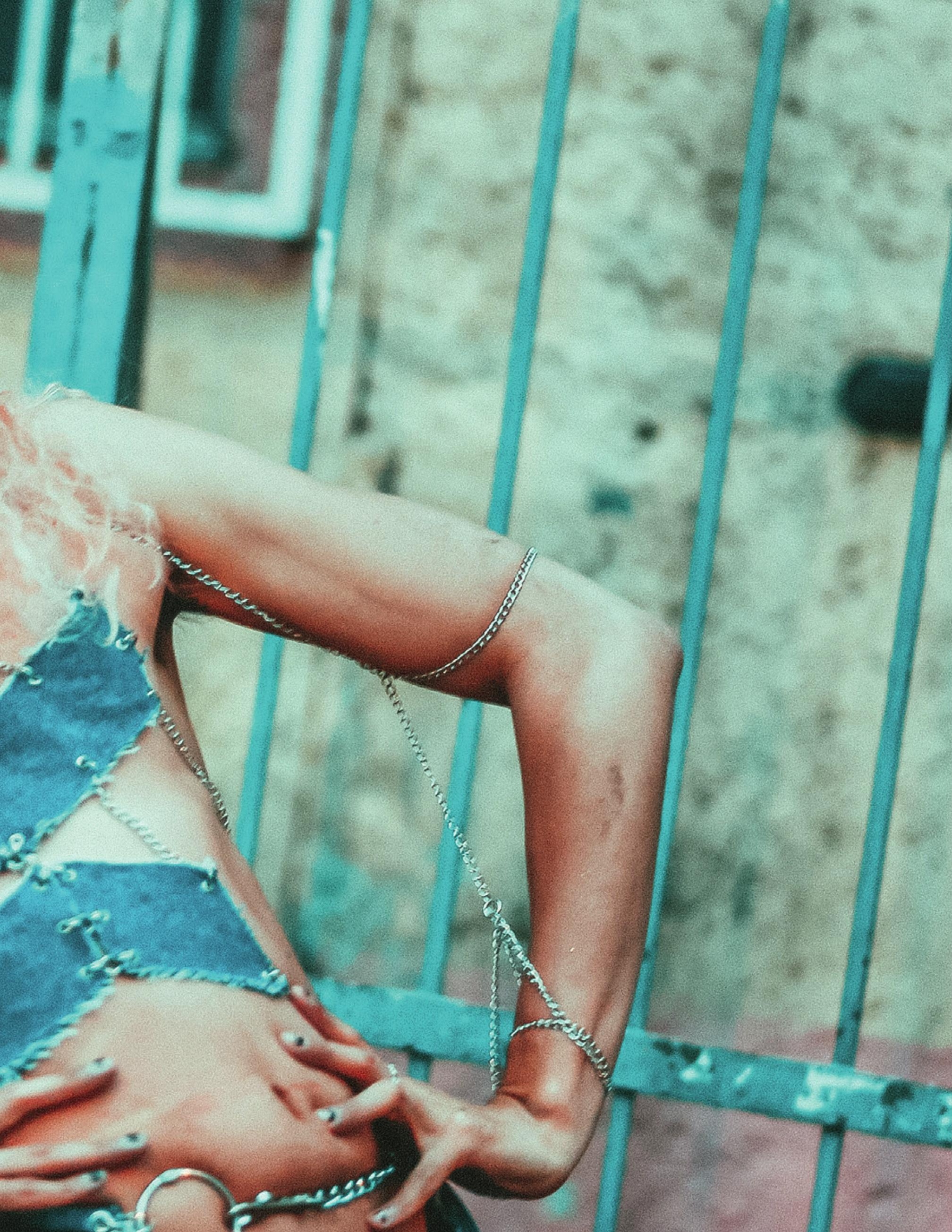




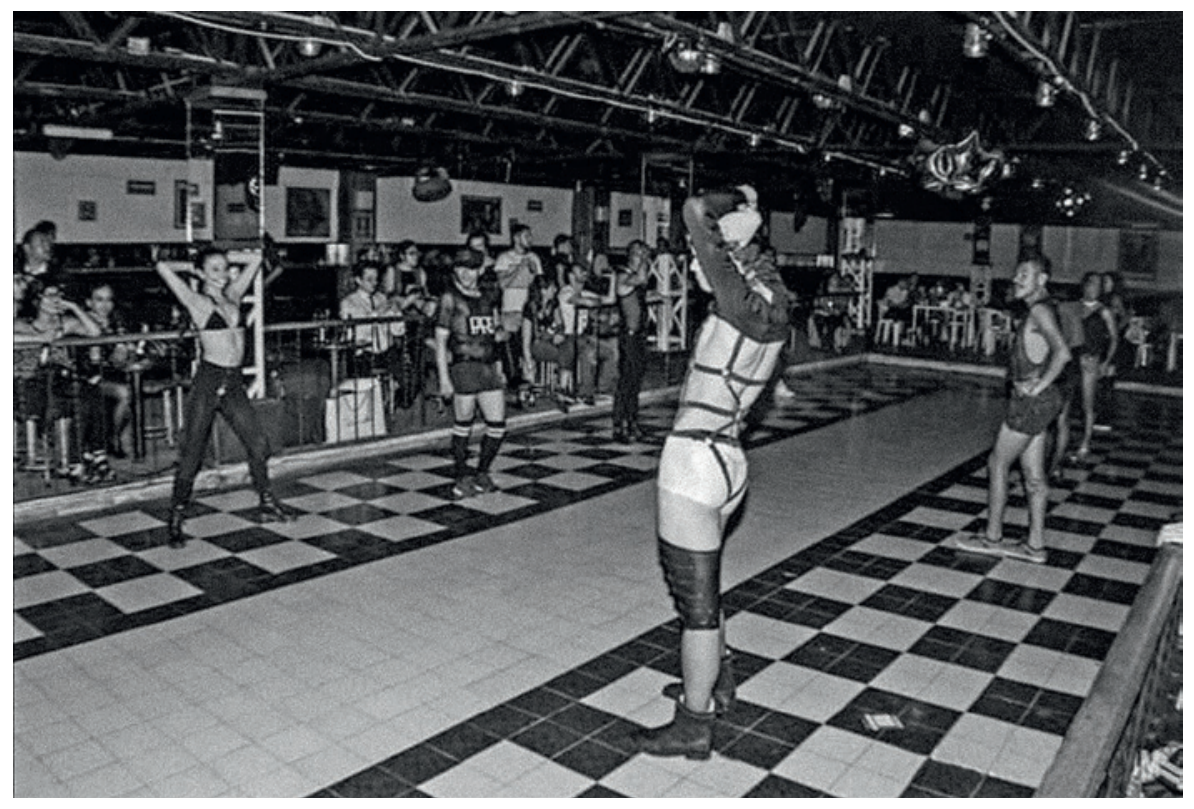

Imagen 2. Alexis Córdoba/Zymalia Drag (2017). Fotografía: Rafael Vázquez. En el No Ball, Ciudad de México

El cuerpo es un texto socialmente construido, un archivo orgánico de la historia de la humanidad como historia de la producción-reproducción sexual, en la que ciertos códigos se naturalizan, otros quedan elípticos y otros son sistemáticamente eliminados o tachados. (Preciado, 2002)

En la actualidad coexisten diversas posibilidades de fuga ante la noción binaria de cuerpo y género, con un amplio espectro de tonalidades matizadas que resignifican y reflejan la diversidad propia de la humanidad. Este nuevo contexto abre un abanico de comunidades que amenazan el orden hegemónico por el simple hecho de ser congruentes con sus voluntades e identidades. No obstante, la presencia de identidades no binarias es un pilar que reincide en la historia de la humanidad y por ello desmonta el mito de que dichas nociones son características de la contemporaneidad. Tales reflexiones circundan los discursos de poder y dominación que subordinan el cuerpo en el ámbito de la danza y en específico en las manifestaciones corporales de la danza voguing.

En la danza el cuerpo va a destiempo del yo, el cuerpo va más adelante del yo que piensa y siente, se pierde, nos perdemos en nosotras mismas, como aquella experiencia alquímica que propone Artaud (1987) en dónde el plomo se transfigura en oro y uno renace en una forma distinta, se aparta de sí, desmonta el sentido del lenguaje y crea una nueva configuración.

Los itinerarios corporales de bailarinas y bailarines ofrecen un caleidoscopio de marcas, huellas, señales, evidencias de posturas apropiadas por ellos, como prácticas corporales que los sitúan como la incorporación de lo social, de un habitus. Margarita Baz (2009) señala que "...aunque para abordar la danza tenemos que comprender el cuerpo, igualmente se sostiene que no se puede entender el cuerpo sin la danza" (p.13).

Tortajada (2011) señala la condición antropológicamente femenina de la danza por "... su cercanía con el cuerpo y el silencio, por ser una manifestación subjetiva, artística, improductiva y "propia" para "débiles" (p.4). La danza históricamente está circunscrita en una concepción binaria de género, es considerada una actividad vinculada a lo femenino, promovida por la división social del trabajo, por la dominación de lo masculino y el desplazamiento de lo femenino a la categoría de débil, improductiva y silenciosa. En la danza se reproducen manifestaciones de género y por consecuencia estereotipos de masculinidad y feminidad, consolida categorías de expresividad, donde los hombres expresan la masculinidad y las mujeres, feminidad. 


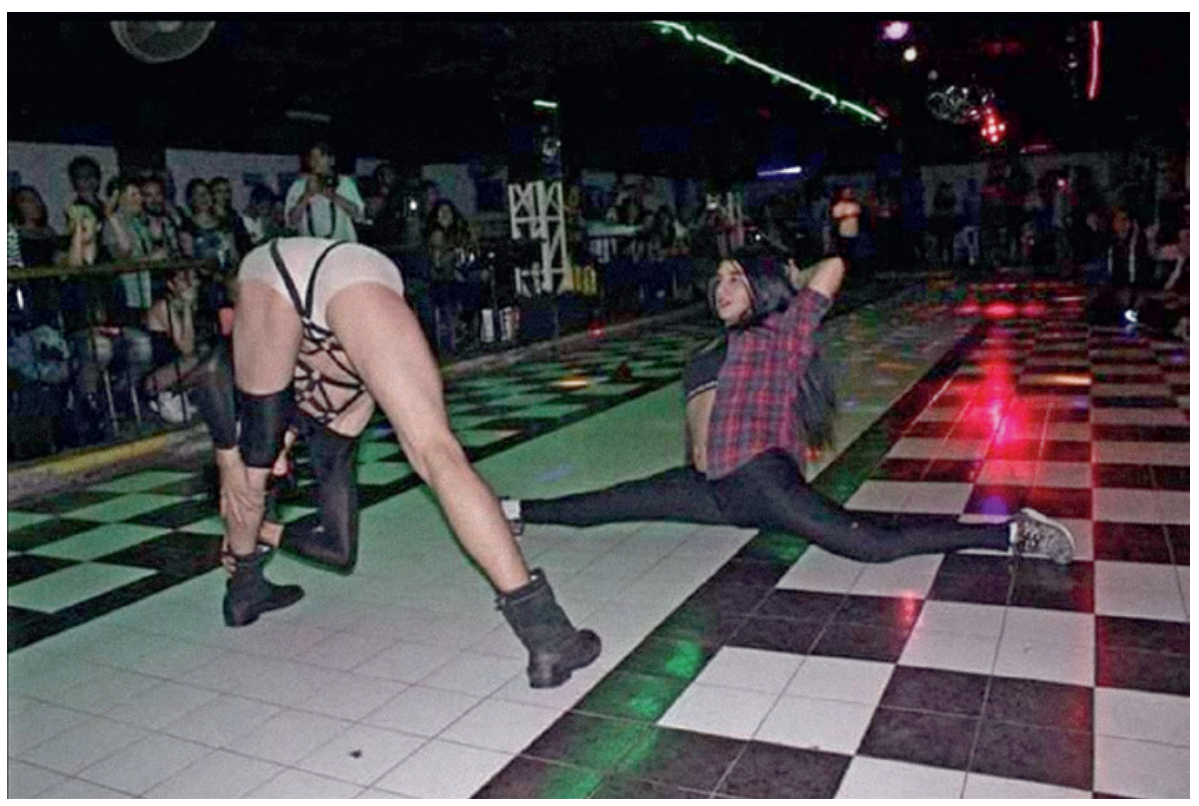

Imagen 3. Alexis Córdoba/Zymalia Drag (2017) Fotografía: Rafael Vázquez.

En el No Ball, Ciudad de México

Es sintomática la irónica exigencia de algunas obras dancísticas o técnicas corporales que exigen del bailarín expresarse desde los atributos de la masculinidad como poderoso, fuerte, valiente e incluso violento. Tales propuestas, sarcásticamente exigen una masculinidad dominante, heterosexual establecida, que reclama del bailarín no binario representar una masculinidad hegemónica que no corresponde a la expresividad elegida por él.

El binario femenino/masculino es una configuración de las dicotomías políticas, económica y sociales de uso del poder. El pensamiento feminista ha polemizado el tema del cuerpo sexuado en el sentido binario y replanteado el problema de la discriminación en términos de género.

La danza voguing se configura como un espacio de resistencia del cuerpo, que encarna la negación de los discursos hegemónicos. Cuerpo como materia y potencia interminable que puede adquirir todas las modalidades de la existencia, que transita el cuerpo finito y contiene lo infinito. Aquí Ixs danzantes voguings están dispuestxs a poner en crisis las nociones finitas sobre la experiencia misma del cuerpo, abren flujos, hacen critica para generar alteridad, hacen de la vida un experimento, desorganizan una estática noción de cuerpo y gestan la permanencia del cambio, en un programa que se disuelve y se reorganiza, como un rizoma que se arboriza y se reconfigura en un nuevo rizoma, eso es el voguing.

Voguear $^{1}$ es disociarse de los cánones social y repensar la individuación, recrearse, desintegrarse y fracturarse en la danza misma, para subvertir aquel orden anatómico impuesto por los discursos hegemónicos. Los cuerpos en el ballroom se disponen encontrarse en un nuevo intersticio conceptual, el carnaval de los cuerpos desviantes que posibilitan una otra forma de estar en el mundo, escape e huida de lo disciplinario.

El voguing es una expresión dancística activista de resistencia contra la marginación de grupos minoritarios integrados por gays afroamericanos, migrantes latinos, transgéneros y queers. Un estilo dancístico y expresión de reafirmación social que tipificó a la comunidad LGBTTTIQ en las décadas de 1980 y parte de los años 90 .

Surge en los barrios de Nueva York en lo más recóndito de la escena underground. Lejos de los reflectores de las pasarelas, estas poses de supermodelos

$1 \quad$ Acción danzante de los voguing. 


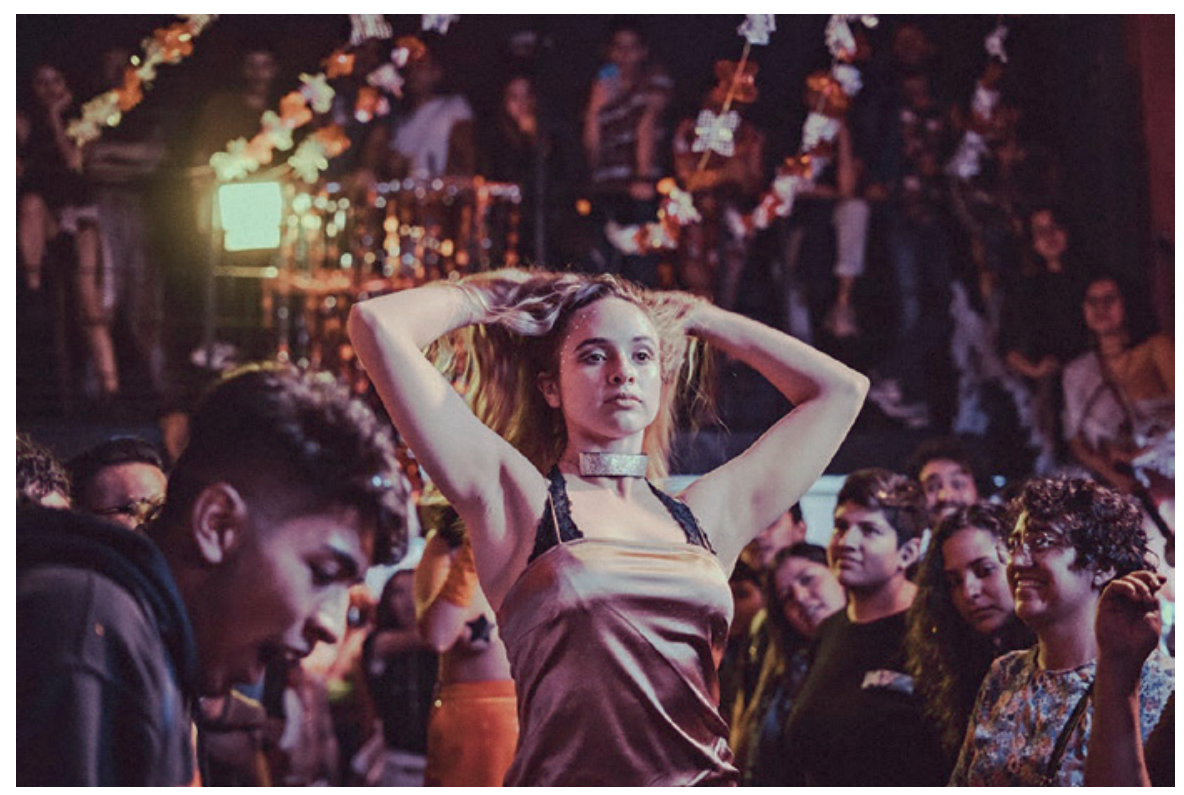

Imagen 4. Bailarina Claudia Ubetta. Fotografía: Luis María Barranco. en la Ciudad de México, Museo del Chopo, UNAM.

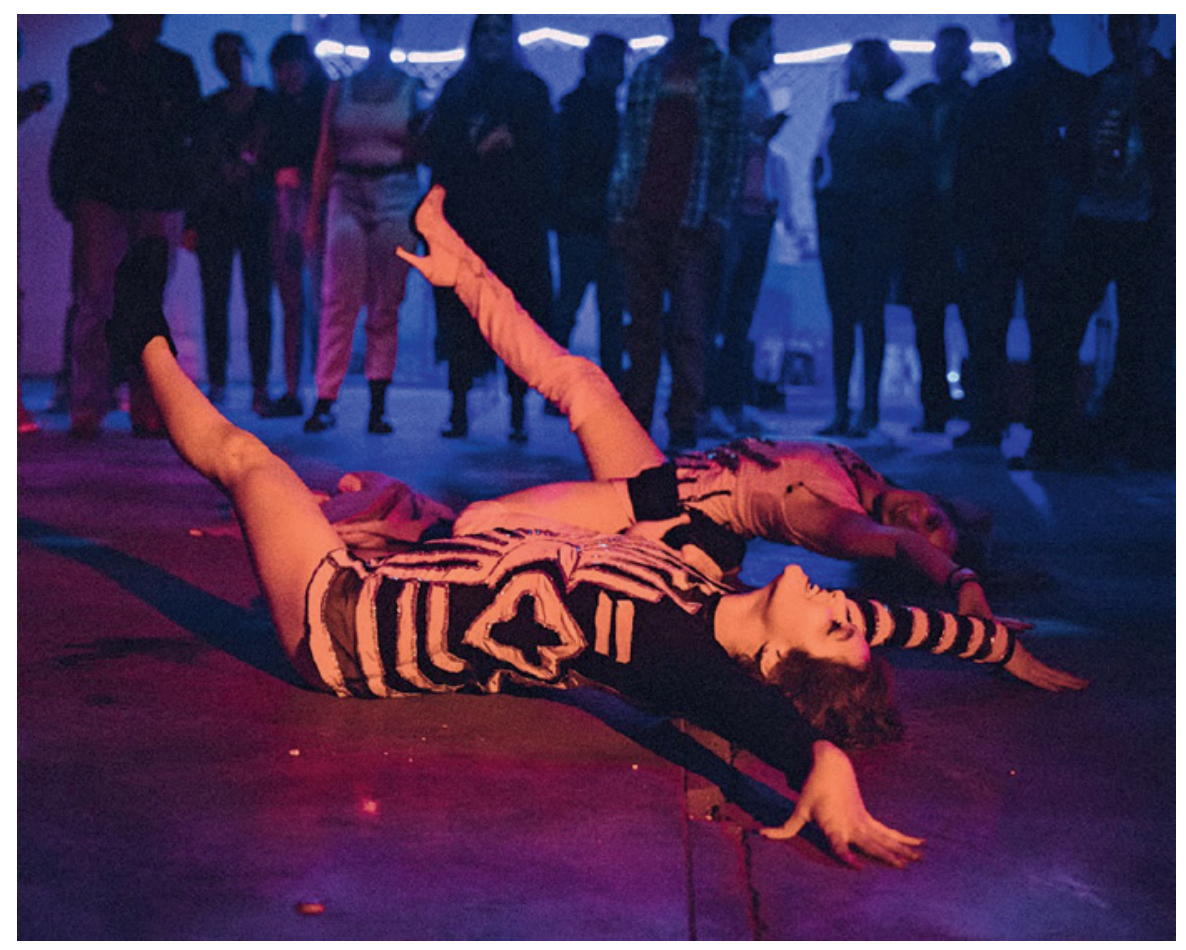

Imagen 5. Bailarina Claudia Ubetta. Fotografía: Luis María Barranco. en la Ciudad de México, Museo del Chopo, UNAM. 
emergen como forma de resistencia inventada por cuerpos criminalizados, racializados, medicalizados y castigados repetidas veces. Acontece bajo el sonido del house, las luces y la indumentaria extravagante como un grito de creatividad y libertad ante la constante represión. Representa varias capas de una subcultura de afroamericanos y latinos que representan un microcosmo de la sociedad, subestimado, clandestino, y desconocido en la cultura popular de los Estados Unidos. Los sujetos voguing luchan con la adversidad que implica la migración, el racismo, la homofobia y la pobreza. Una mirada a las vidas y problemas de sus protagonistas y la fuerza, orgullo y ánimo que estas debían mantener para sobrevivir en un mundo "rico y blanco".

Willi Ninja - cofundador de House of Ninja- club en que se bailaba el voguing; junto a Archie Burnett, crean el baile inspirado en las poses de revistas de moda, artes marciales, ballet, gimnasia, los jeroglíficos y la pantomima. La conjunción de estos elementos funda una danza que invita a todos a bailar. No siempre componen coreografías, básicamente son movimientos improvisados y oriundos de lo más íntimo del ser, un acontecimiento, una fiesta. Para los voguers ${ }^{2}$ originales esta danza activista no era un baile más de tendencia y de moda, ni solamente una armonía de movimientos excéntricos, era una forma de expresión que indicaba libertad, desinhibición y claro, una fuerte necesidad de dejar de aparentar lo que no eran.

Tomó popularidad gracias al documental Paris Is Burnig (Livingston, 1991), un filme sobre la cultura del ballroom a finales de los 80 s en Nueva York que capturó una parte de esta década desconocida para muchos, con raíces en una cultura fascinante, y el icónico video de Madonna (Fincher, 1990) que popularizó el voguing.

En 1977, una de las reinas más relevantes, Crystal Labeija, organizó un ball con el nombre de su propia casa, House of Labeija, y sin saberlo marcó un antes y un después, incluso instauró el sistema de casas de la cultura LGBTTTIQ, que sirven como competencia en los balls pero también son un refugio de cuidado, protección e inclusión. Al frente de cada una de ellas hay una madre, quienes son

2 Bailarines voguing. las mentoras que se encargan de proteger, como en una familia, a los miembros de la casa.

Los más destacados miembros de este movimiento, se refieren a Pepper Labeija, Dorian Corey, Angie Xtravaganza y Willi Ninja. Muchos de los que participaban buscando ganar un trofeo pertenecían a las distintas casas del movimiento, un término asimilado también del mundo de la moda, que aquí adquiere un significado similar al de una suerte de familia, o grupo social, con unas características representativas propias. Del mismo modo, aquellas casas y participantes que reiteradamente ganaban en estas competiciones, adquirían un estatus casi legendario para el resto del movimiento.

Títulos como "casa" o "madre" enfatizan cómo esta cultura adaptaba términos del mundo blanco heterosexual con nuevos significados. Así las casas eran las nuevas familias para los jóvenes queer cuya orientación sexual les había llevado muchas veces a tener que romper con sus familias. Las casas o houses son la base del voguing, espacio de contención socio-afectivo que genera la conformación de nuevas nociones de familia. Deciden reproducirse no por los genes sino por las ideas, performances, pasarelas basadas en estrellas de cine y modelos de pasarela. Lo que detona otras razones que las personas tienen para formar una familia: como el afecto que les une, su ideología, o algún proyecto en común.

En la Ciudad de México el voguing resurge y retoma fuerza activista de resistencia alrededor de 2015, veinte años después de sus inicios en Estados Unidos. Se instituyen las primeras casas en México lideradas por sus respectivas "madres". Entre ellas encontramos cuatro casas: 1. "House of Mamis" guiada por la "madre" Eduardo Mendoza; 2. "House of Drag" por la "madre" Bryan Cárdenas; 3. "House of Machos" guiada por Anuar Alvarado 4. "House of Apocalipstick por la "madre" Omar Feliciano (Franka Polarí).

Existe una relación histórica entre el vogue y género, comenta en entrevista Miguel Fuentes ${ }^{3}$ de House of Apocalipstiky "siempre ha existido una contestación a la forma rígida binaria tanto

\footnotetext{
3 Miguel Fuentes, voguero en entrevista a VICE en español. Familias Diversas - Ep. 3, Disponible en «https://www.youtube.com/watch?v=qMLqkrkRg9o»
} 
de sexo como de género, que ha participado la comunidad gay, lesbiana y trans en la posición de marginalidad de muchos enfoques, no solamente económicos, sino también social y de identidad de género". En México el voguing es activismo para promover una nueva forma de pensar las estructuras familiares, afirma Franka Polari "madre" de House of Apocalipstiky aclara que "somos la casa más estructurada, más jerarquizada, con pretexto de justificar la estética vogue y la cultura ballroom para crear afinidad y lazos."4

El ballroom es una fiesta donde reina la diversidad, se realiza de manera periódica y quienes asistan son testigos de diferentes competencias que se desarrollan en una pasarela. Hay una persona que presenta, anima el evento y alienta al público a aplaudir, chasquear sus dedos en señal de aprobación y a gritar por los participantes que llegan montados con sus looks súper elaborados y llamativos; y claro hay un jurado (tanto o más montado que los competidores) que decide quién gana, con un criterio que nadie debate demasiado. Una suerte de espacio heterotópico, un «contra-espacio» donde se suspenden las normas morales que rigen todo otro lugar, «utopías localizadas» que encuentran un lugar provisional o un puerto de excepción. Algo así como las «heterotopías de la desviación» de Foucault, que representan "lugares que la sociedad sitúa en sus márgenes, en las zonas vacías que la rodean, reservados a individuos cuyo comportamiento es desviante con respecto a la media o a la norma exigida" (Foucault, 1967).

En el ballroom acontece competencias entre cuerpos que irrumpen frenéticamente una pasarela para expresarse con libertad, competir y demostrar que son los mejores, una especie de sobre abundancia ${ }^{5}$ de la experiencia que expone el cuerpo a una fuerza original que potencia la vida y genera una dionisíaca manifestación del cuerpo que danza y resiste, una pulsión de la vida misma sin diferenciación ni limite. La vida concebida “...

$4 \quad$ Franka Polari, madre de la casa Apocalipstiky en entrevista a VICE en español. Familias Diversas - Ep. 3 « https://www. youtube.com/watch?v=qMLqkrkRg9o»

5 La afirmación dionisiaca de la vida solo se entiende desde la base de un exceso de fuerza y sobreabundancia de vida. (Guervós, 2000, p. 245). como <proceso > un devenir sin meta ni fin más allá de la verdad y de la no verdad, creatividad, destrucción y construcción <lo dionisíaco>" (Guervós, 2000, p. 245).

En el ballroom las fuerzas entran en colisión, explotan e irrumpen la voluptuosidad de los cuerpos extravagantes que con movimientos retorcidos se desplazan por la pasarela, un espacio fantástico para construir un doble en sus vanidades brillantes que relucen el narcisismo desviante. Estos cuerpos que migran a un espacio otro para disponerse de forma alterna e huir del sentido hegemónico. Este espacio de teatralidades queer me remite a la idea de $<<$ no más obra maestra $>>$ de Artaud,

...aunque el gesto teatral sea violento es también desinteresado, y que el teatro enseña justamente la inutilidad de la acción, que una vez cometida no ha de repetirse, y la utilidad superior del estado inutilizado por la acción, que una vez restaurado produce la sublimación. (Artaud, 2013, p. 92)

En la actualidad la apropiación cultural sufrida por el ballroom ha sido extensa, voraz y codiciosa. Los especialistas consideran una incorporación positiva a la cultura popular, con un creciente y notorio consumo, así como un incremento sustancial en sus prácticas y visibilización entre las diferentes capas de la comunidad: queer, gay, homosexual, transgénero, drag y cisgenero.

De todos los elementos que componen la cultura ballroom, el más expresivo y espectacular, es el voguing - danza activista de resistencia, propio de los miembros de esa cultura. Debe su nombre a la famosa revista de moda Vogue, debido a que tomaban de las modelos de revista la feminidad de sus movimientos, sus poses por la claridad de sus formas y la liberación que fomenta su práctica.

Las batallas de voguing son las que generan mayor expectativa del público, donde suceden decenas de categorías entre las que destacan runway (mejores desplazamientos en una pasarela), realness (capacidad de representar un personaje específico), face (belleza de tu rostro) o sex siren (capacidad de excitar los jueces), y otras. Debido a la gran diversidad de género de los participantes, es habitual en el ballroom que las competencias se dividan en categorías según las identidades de los participantes, entre ellas están: butch queens 


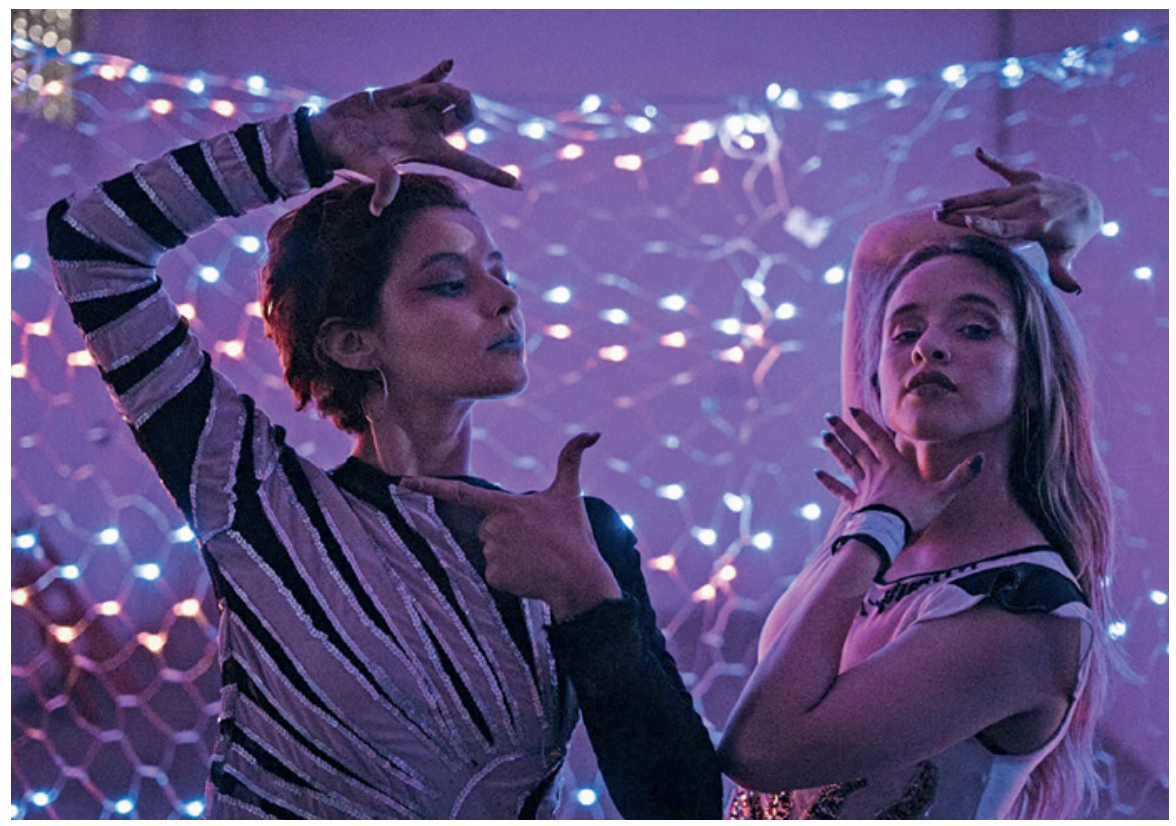

Imagen 6. Bailarina Claudia Ubetta. Fotografía: Luis María Barranco. en la Ciudad de México, Museo del Chopo, UNAM.

(hombres gays), femme queens (mujeres trans), drags (hombres gays vestidos de mujer), women (mujeres cisgéneros), men (hombres cishet) y butches (hombres trans o mujeres con apariencia masculina), en ocasiones no se abren todas las categorías y otras se integran una competencia open-to-all en que se aglutinan algunas categorias. Además, es posible abrir categorías según el estatus de los participantes en la escena ballroom: virgin o beginners (principiantes que se entrenan en le ballroom), normal (para los statements y stars) y legendary (legends o icons con este estatus ha muchos años).

Por otro lado, no solo intervienen los participantes y el público, sino también los promotores y sponsors que garantizan la viabilidad de las competencias; los jueces que determinan los ganadores; los DJs que llevan Beats de vogue; los MCs o commentators que animan a que los participantes den lo mejor de sí; el público que "canta" los nombres de las houses para apoyar a los bailarines; $y$ todas las personas que están detrás de las costosas producciones que se ven en las pasarelas, diseñadores, peluqueros y estilistas.

A estas prácticas imitativas y representativas Judith Butler (2004) llamó performatividad de género, a partir de la observación de fenómenos de las draggs queens neoyorquinas y de los "ecosistemas" entorno a las llamadas "casas" del Bronx emprendió una minuciosa y radical revisión del concepto de género.

El cuerpo no es una realidad material fáctica o idéntica a sí misma; es una materialidad cargada de significado (...) y la manera de sostener ese significado es fundamentalmente dramática. Cuando digo dramático me refiero a que el cuerpo no es simplemente materia sino una continua e incesante materialización de posibilidades. Uno no es simplemente un cuerpo, sino, de una manera clave, uno se hace su propio cuerpo y, de hecho, uno se hace su propio cuerpo de manera distinta a como se hacen sus cuerpos sus contemporáneos y a cómo se lo hicieron sus predecesores y a cómo se lo harán sus sucesores. $(2004$, p. 189)

"Lo que constituye la persistencia del cuerpo, sus contornos, sus movimientos, es lo material; pero la materialidad debe pensarse como un efecto del poder, su efecto más productivo" (Judith Butler, 1990).

Derrida (1989) menciona que las palabras tienen el poder de crear realidad, el comportamiento y acciones del individuo tiene el poder de construir la realidad de los cuerpos. Las expresiones 


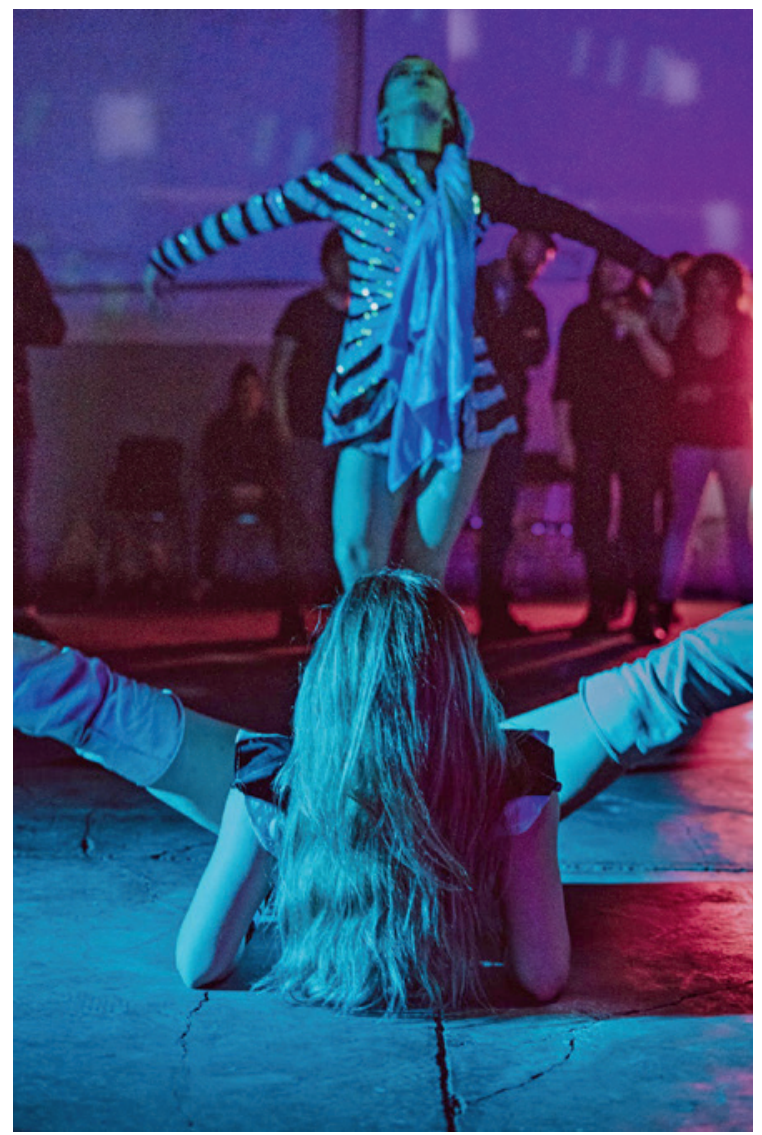

peyorativas remiten siempre a una convención, un patrón de comportamiento autorizado que permite que las palabras y las acciones tengan el poder de transformar la realidad.

En las pasarelas del ballroom, los performers voguing ejercen su derecho de proclamar su existencia, re-significan su estar en el mundo desde la deconstrucción de las identidades estigmatizadas (Fonseca, 2009, pp. 43-60), apropia su cuerpo como disidente y subversivo.

La forma en que se modernizan los cuerpos son las formas que se construyen las subjetividades del cuerpo. Deleuze dice que el cuerpo está constantemente fugando por todos lados. La performatividad de Butler señala que hay que estar regresando a ella para reconstruir las nociones del cuerpo. Grotowski habla de este cuerpo que está vivo en la transformación, y readaptando al contexto. Se adhiere desfasándose de él, no adelantado sino desfasado, yendo hacia atrás, adelante, arriba
Imagen 7. Bailarina Claudia Ubetta. Fotografía: Luis María Barranco. en la Ciudad de México, Museo del Chopo, UNAM.

y abajo, una aparente objetividad no lineal sino expansiva.

El quehacer desviante refleja y comparte un saber recíproco, un modo de hacer para poder acceder y estar en los contextos, entre las múltiples configuraciones de vida social. Lo anterior los sitúa en los espacios encarnados al gestar y disponer el mundo con el fin de dar sentido a sus acciones. La socióloga Joanne Entwistle (2002), afirma que "los cuerpos humanos son el producto de una dialéctica entre la naturaleza y la cultura" (p. 44).

Profundizar en estas prácticas corporales, es posiblemente orientarse por un quehacer corporal y su estado en el espacio social, su sentido de lugar (actual y potencial) trasmutado en "un sentido de colocación que rige su propia experiencia del lugar ocupado, definido absoluta y, sobre todo, relacionalmente, como puesto, y los comportamientos que ha de seguir para mantenerlo 
"conservar su puesto", y mantenerse en él "quedarse en su lugar" ..." (Bourdieu, 1999, p. 243).

Tal quehacer refleja y comparte un saber recíproco, un modo de hacer para poder acceder y estar en los contextos, entre las múltiples configuraciones de vida social. Lo anterior los sitúa en los espacios encarnados al gestar y disponer el mundo con el fin de dar sentido a sus acciones. La socióloga Joanne Entwistle (2002) afirma que "Ios cuerpos humanos son el producto de una dialéctica entre la naturaleza y la cultura" (p. 44).

Sobre la naturaleza corporal propia del ser humano, la reflexión antropológica y filosófica de Max Scheler defiende la unidad del ser humano contra todo tipo de dualismo según $<<$ mente/ cuerpo>>, destaca el hecho de que el hombre se diferencia de los animales porque, al mismo tiempo, es un cuerpo y tiene un cuerpo. Esto permite distanciarse subjetivamente de su cuerpo y aplicar su capacidad crítica, irónica, afectiva, entre otras, sobre la realidad.

Según Duch y Melich (2005) el ser humano puede ser descrito e interpretado a partir de dos formas de presencia en el mundo de su cuerpo, como si se tratará de dos cuerpos, el <<cuerpo>> (Körper) una cosa entre las cosas, que se encuentra en un lugar cualquiera del continuum espacio-temporal; y como cuerpo (Leib) un sistema concéntricamente cerrado en torno a un centro absoluto, en un espacio y un tiempo con direcciones absolutas (p. 155). Resalta que el cuerpo (Leib) ejerce la función de lugar de intercambio entre el espíritu y la naturaleza, entre la cultura y la naturaleza, entre los hechos y su recepción, entre el sentido y la causalidad. Duch alude que estos dos sistemas <<cuerpo>> (Körper) y cuerpo (Leib), es un sistema inseparable porque constituyen $<<$ una y la misma cosa>>. Esta duplicidad - Körper y Leib - inherente a la existencia humana hace posibles auténticas rupturas e hiatos significativos en la forma histórica de la aparición del ser humano en su mundo, solo comprendidos si tenemos en cuenta la movilidad - paso incesante de la <<naturaleza >> a la <<cultura>> frecuentemente sometida la existencia humana -. El hombre, consecuencia de su posición excéntrica, constantemente se ve obligado a encontrar un equilibrio, a menudo inestable y precario, entre el <<ser-cuerpo>> (Körper) y de <<tener-cuerpo>>
(Leib), el cuerpo al mismo tiempo condición y objeto (p. 156). Como señala Judith Butler (1999), en las sociedades occidentales y occidentalizadas existe una relación mimética entre sexo, género, sexualidad y deseo, de forma que existe una inteligibilidad unívoca al interior del sistema de género binario. Para Butler, la creación y recreaciónn del género se define como una puesta en escena de actos ritualizados que naturalizan la univocidad entre estos cuatro componentes, es decir, el género es entendido como un acto performativo. De esa manera, los anclajes que constituirían el género inteligible se hallan en función de las relaciones y las asimetrías entre hombres y mujeres: tanto prácticas como sujetos y objetos de deseo refuerzan la pertenencia a uno u otro género. El género es parte que determina al sujeto y se construye a través de las relaciones de poder, las restricciones normativas que no solo producen sino que además regulan los diversos seres corporales.

Durante buena parte de la modernidad revoluciones somatopolíicas impulsaron movimientos por la redefinición del estatuto del cuerpo frente a las prácticas que definen como se gobierna este cuerpo y frente a los aparatos de verificación, es decir, a las prácticas que se permiten decir cuando un cuerpo es verdadero o falso, normal o patológico, sano o enfermo. La sucesión de movimientos de resistencias instigó fuertes críticas a los aparatos disciplinarios. En los años 80 aparecen un conjunto de movimientos de resistencia antineoliberal, de movimientos contra el régimen farmacopornográfico, concepto paralelo a lo que Foucault llamó régimen disciplinario que se diferencia de este por la forma como opera. Según Paul B. Preciado (1970) con el régimen farmacopornográfico surge un nuevo modelo de control sintético que actúa de forma casi invisible desde el interior del cuerpo mismo, un efecto molecular que modifica la composición química del individuo y que propone un nuevo modelo de control del cuerpo a partir de las grandes industrias del siglo XX: la farmacéutica y la pornográfica.

Paul Preciado (1970) alude que el resultado de este dispositivo es la invención de una estética política de la diferencia sexual, la invención de la masculinidad y de la feminidad como verdades anatómicas dentro del aparato de verificación científico, una de las particularidades de la compleja situación de los movimientos políticos feministas 


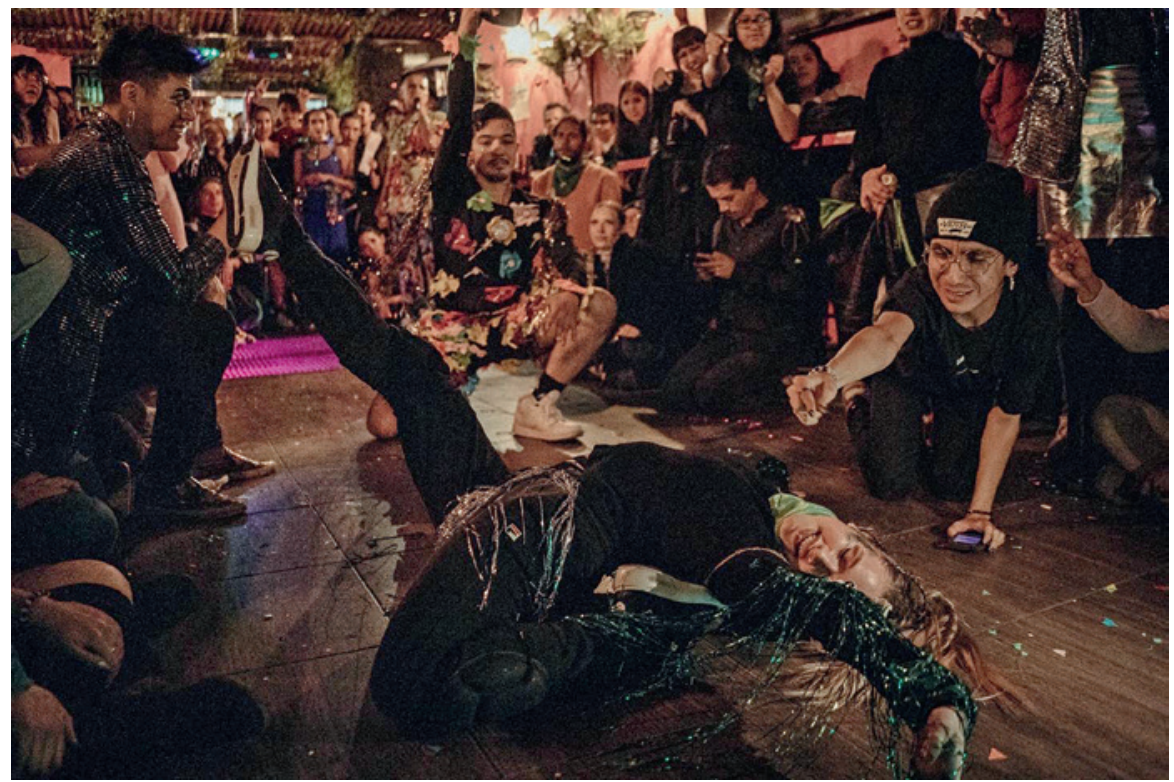

Imagen 8. Bailarina Claudia Ubetta. Fotografía: Luis María Barranco. en la Ciudad de México, Museo del Chopo, UNAM

y homosexuales. Es decir, estamos desarticulando constantemente lenguajes empoderados científicamente.

Podemos mirarnos como una estandarización performativa como el resultado de un enorme proceso de reproducción performativa y la imposición de una estética política visual de la diferenciación sexual. Ese proceso Paul B. Preciado lo denominó como la primera industrialización de la sexualidad. El cuerpo como última de las cápsulas biopolíticas, es una cápsula disciplinaria curiosa, porque es la única que tiene la voluntad de decir yo, por lo tanto se identifica con los aparatos de normalización que la produce, esa es una de la dificultades de la subversión política, en respuesta a ello nuestro grito retorcido contra la opresión. "Lo que constituye la persistencia del cuerpo, sus contornos, sus movimientos, es lo material; pero la materialidad debe pensarse como un efecto del poder, su efecto más productivo" (Butler, 2018).

En Cuerpos que importan, Butler (2018) reformula la cuestión de la materialidad de los cuerpos cuando afirma que la performatividad se trata de un poder reiterativo del discurso para producir los fenómenos que nos regulan y que se nos imponen. De modo tal que la construcción del género no es una acto único ni un proceso iniciado por un sujeto, sino que estamos ante procesos que sea realizan en el tiempo. El género en sí mismo es un proceso temporal que opera a través de la reiteración de normas, como efecto sedimentado de una práctica reiterativa o ritual. En esta reintegración se encuentran los espacios, las fisuras, brechas que representan zonas inestables de la constitución del género, de su construcción, lo que escapa o supera a la norma, lo que no puede terminar de definirse mediante la repetición de la norma.

A manera de conclusión abierta queda la reflexión en torno a las nuevas representaciones ballroons como un dispositivo que peligra a recaer en las nuevas configuraciones de sistemas de control de la sociedad actual, el boom del resurgimiento del voguing y la creación de espacios institucionalizados que reconfiguran un nuevo patrón de conducta preestablecida, un lugar específico para volcar la histriónica sensualidad erótica de los gestos performativos disidentes, una red donde se entrecruzan instituciones y discursos hegemónicos.

Rememoro aquel espacio horizontal de Bataille (2008), que oculta la bajeza material y heterogénea, que abre lugar para el goce como la culminación de la sexualidad humana, que transgrede 


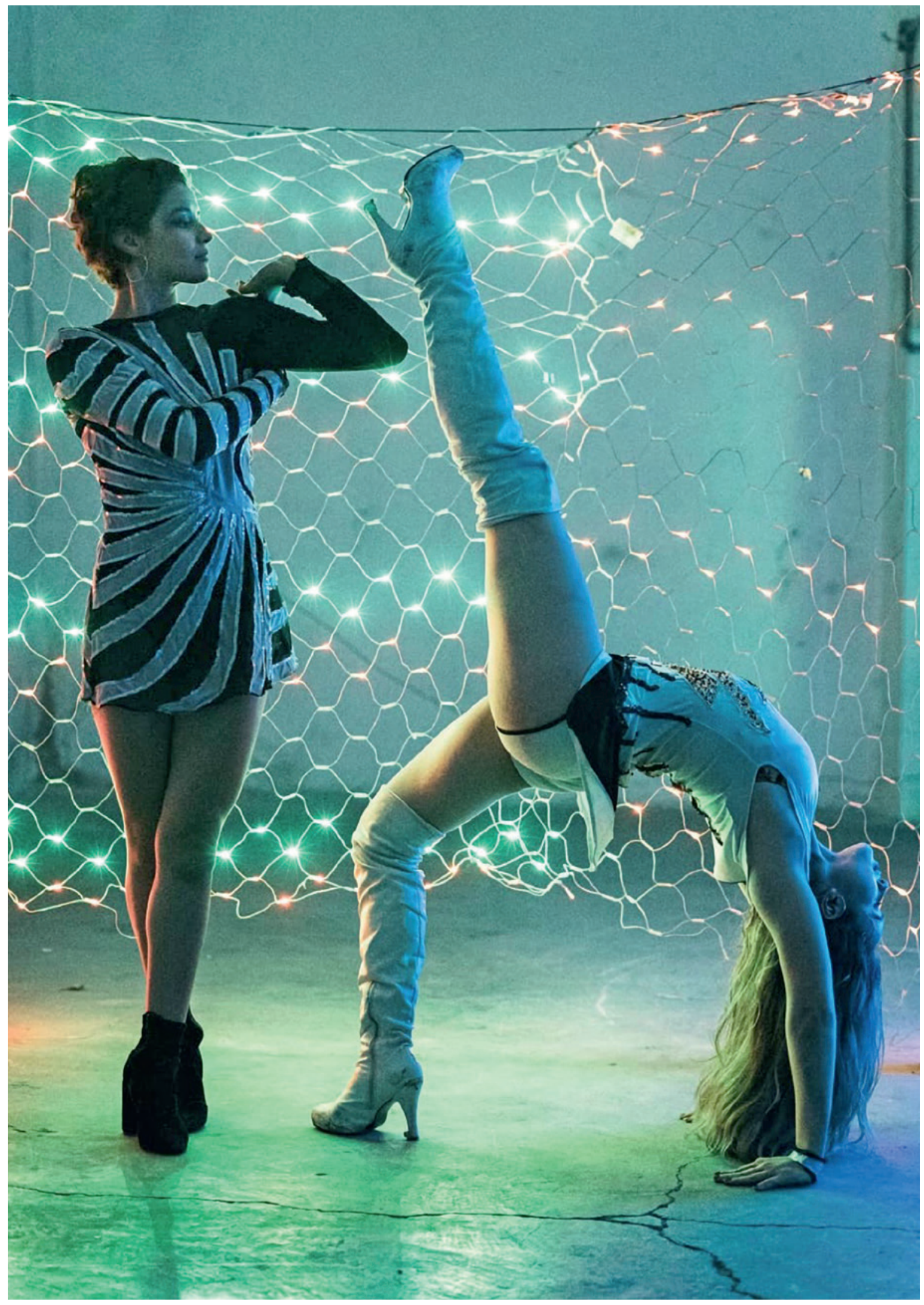

Imagen 9. Bailarina Claudia Ubetta. Fotografía: Luis María Barranco. en la Ciudad de México, Museo del Chopo, UNAM. 
el tabú y permite que la infracción y el interdicto se acompañen. Para Bataille en la individuación surge la pulsión erótica para continuarnos en el ser, incluso en la muerte, aquí la experiencia erótica es horizontal, frente al sistema vertical de prohibiciones que a su vez es condición de posibilidad del erotismo. Según Foucault (1994) es una de las categorías fundamentales del "interdicto" experiencia del límite que el sujeto extrae de sí mismo, como la muerte de Dios en Nietzsche. En Bataille transgredir no es oponerse al límite y tampoco negarlo sino afirmarlo, abrazar el limite como ilimitado, como desmesura que solo se comprende en la experiencia de la muerte de Dios. "Y así realiza el arte según Nietzsche un triple aspecto: el arte redime al que conoce, el arte redime al que actúa, el arte como redención del que sufre" (Guervós, 2000, p. 262).

\section{Referencias}

Artaud, A. (2014). El teatro y su doble, Buenos Aires, Argentina: Editorial El cuenco de Plata.

Bataille, G. (2008). El Erotismo, México: Tusquets.

Baz, M. (2009). “Cuerpo y otredad en la danza”, (pp. 13-30), Ed. Tramas. disponible en «http:// 148.206.107.15/ biblioteca digital/articulos/6-477-6893biu.pdf»

Bernard, M. (1985). El cuerpo. Un fenómeno ambivalente, Buenos Aires: Editorial Paidós.

Borgdorff, H. El debate sobre la investigación en las artes. https://tinyurl.com/y3yaz35w

Castillo, J. (2008). Investigación - Acción, disponible en «http:// www.monografias.com/tra- bajos15/investigacion-accion/ investigacion-accion.shtml\#ORIGEN»

Bourdieu, P. (1991). El sentido práctico, Madrid: Ed. Taurus.

Butler, J. (2018). El género en disputa. El género y a subversión de la identidad, México: Editorial Paidós.

(2019). Cuerpos aliados y lucha política. Hacia una teoría performativa de la asamblea, México: Editorial Paidós.

(2018). Deshacer el género, México: Editorial

Paidós.

(2018). Cuerpos que importan, México: Editorial

Paidós.
Chacón, K., y Hernández R. (2016). Otras Masculinidades: Prácticas corporales y danza, Revista Nóesis, 25(diciembre), disponible en «file:///Users/wak/Desktop/ Lecturas\%20 Doctorado/Dialnet-OtrasMasculinidades-5763011.pdf»

Coll-Planas, G. (2012). La carne y la metáfora. Una reflexión sobre el cuerpo en la teoría queer, España: Ed. Egales.

Duby, G., y Perrot, M. (2016). Historia de las Mujeres. La antigüedad, Madrid: Ed. Tau ros.

Deleuze, G., y Guattari, F. (1997). Mil mesetas, Madrid: Pre-Textos.

Deleuze, G. (17 de marzo de 1987).¿Qué es el acto de creación?, (conferencia) en la Femis (Escuela Superior de Imagen y Sonido) Disponible en «https://www.youtube.com/ watch?v=GYGbL5tyi-E\#t=256»

Deleuze, G. (1990). ¿Qué es un dispositivo? «http://serbal.pntic. mec.es/ cmunoz11/fanlo74.pdf» Recuperado el 16 de agosto de 2012 .

Derrida, J. (1989). El teatro de la crueldad y la clausura de la representación, en la escritura y la diferencia, Barcelona: Anthropos.

Duch, L., y Mèlich, J.C. (2005). Escenarios de la Corporeidad. Antropología de la vida cotidiana 2/1, Madrid: Editorial Trotta.

Entwistle, J. (2002). El cuerpo y la moda. Una visión sociológica, México: Ed. Paidós.

Fonseca, C., y Quintero, M. (2009). La Teoría Queer: la de-construcción de las sexualidades periféricas. Sociológica, 24(69), pp.43-60, [online], ISSN 2007-8358.

Foucault, M., y Garzón del Camino, A. (1976). Vigilar y castigar. Nacimiento de la prisión, México: Siglo XXI editores.

Foucault, M. (1978). The History of Sexuality, Vol. 1: An Indroduction, New York: Pantheon.

(1981a), "Los cuerpos dóciles", en Vigilar y castigar, México: Siglo XXI Editores.

(1981b) "La hipótesis represiva" en Historia de la Sexualidad. La voluntad de saber, México: Siglo XXI Editores.

(1992). Genealogía del Racismo: de la guerra de las razas a racismo de Estado, Madrid: La Piqueta.

(1998). Technologies of the Self: A Seminar with Michel Foucault, L. Martin, H. Gutman, y P. Hutton, (Eds.), University of Massachusetts Press. 
Grosz, E. (1994). Volatile Bodies: toward a corporeal feminism, Bloomington: Indiana University Press.

(1995). Space, Time, and Perversion: essays on the politics of bodies, New York: Routledge.

Guattari, F., y Rolnik, S. (2013). Micropolítica. Cartografías del deseo, Colección Nociones comunes.

Guervós, L. E. (2000). El arte como función de la vida en F. Nietzsche, Contrastes. Re- vista Interdisciplinar de Filosofía, $V$, pp. 241-260.

Halberstam. J. (2018). El arte queer del fracaso, España: Editorial Egales.

Hammersley, M., y Atkinson, P. (1983). Ethnography. Principles in practice, Londres; Nueva York: Tavistock.

Islas, H. (2001). De la historia al cuerpo y del cuerpo a la danza: elementos metodológicos para la investigación histórica de la danza, México: Conaculta.

Kulka, T. (2011). El Kitsch, España: Ed. Casimiro.

Benjamin, W. (2003). La obra de arte en la época de su reproductibilidad técnica, México: Ítaca.

Leboulch, J. (1991). Hacia una ciencia del movimiento humano. Introducción a la psicokinética, México: Paidós

Le Brenton, D. (2002). La sociología del cuerpo, Buenos Aires: Ed. Nueva Visión.

(2002). Antropología del cuerpo y modernidad,

Buenos Aires: Ed. Nueva Visión.

(2005). Cuerpo sensible, Buenos Aires: Ed. Metales

pesados.

(2000). Elogio del caminar, Buenos Aires: Ed. Siruela

Lepecki, A. (2006). Agotar la danza. Performance y política del movimiento, España: Universidad de Alcalá.

Lipovetsky, G., y Serroy, J. (2015). La estetización del mundo. Vivir en la época del capitalismo artístico, Barcelona: Ed. Anagrama.

Lowe, A. (1985). El lenguaje del cuerpo. Dinámica física de la estructura del carácter, Barcelona: Ed. Herder.

Nancy, J.L. (2003). Corpus, Madrid: Ed. Arena Libros.

Perniola, M. (2016). El arte expandido, Madrid: Ed. Casimiro Libros.
Preciado, Paul B. (2002). Manifiesto contrasexual, España: Ed. Anagrama.

Preciado, P. B. (2010). Pornotopía. Arquitectura y sexualidad en $<$ Playboy> durante la guerra fría, España: Anagrama. (2008). Testo Yonqui, España: Espasa Calpe.

Rodríguez, P. (2000). Dios nació mujer. La invención del concepto de Dios y la sumisión de la mujer, dos historias paralelas, España: Suma de letras.

Rucovsky, M. (2016). Cuerpos en escena. Materialidad y cuerpo en Judith Butler y Paul B. Preciado, España: Editorial Egales.

Solares, B. (2001). Los lenguajes del símbolo. Investigaciones de hermenéutica simbólica, España: Editorial Antrhopos.

Tortajada, M. (2006). Danza y poder I (1920-1963) / Danza y poder II (1963-1980), México: Conaculta/INBA/Cenidi Danza/Cenart.

Tortajada, M. (2007). El concepto moderno del ballet: Los ballets rusos y el retorno de la danza masculina, México: Casa del Tiempo

(2008). "Masculinidades alternativas: Construcción en la danza de Nijinsky y Limón", en 1er. Encuentro Latinoamericano y del Caribe. La sexualidad frente a la sociedad, (pp. 235-260), México: Fundación Arcoíris.

(2011). Danza y Género, México: Instituto Nacional de Bellas Artes.

Revista danza y política. (2013). Regiones suplemento de antropología, número 50

Sánchez, J. A. (2016). Ética y representación, Madrid: Editorial Paso de Gato.

\section{En línea}

Livingston, J. (1990). Paris Is Burning. American documentary film, (video), disponible en «https://www.youtube.com/ watch?v=D8NnWqHm9bY»

Fincher, D. (1990). Madonna's soundtrack album 'I'm Breathless' for the motion picture, (video), disponible en «https://www. youtube.com/watch?v=GuJQSAiODql»

Miguel Fuentes, en entrevista a VICE en español. Familias Diversas - Ep. 3, disponible en «https://www.youtube.com/ watch?v=qMLqkrkRg9o» 